\title{
Correlation of Cerebroplacental Ratio (CPR) With Adverse Perinatal Outcome in Singleton Pregnancies
}

\author{
BERTHOLD GRÜTTNER*, JESSIKA RATIU*, DOMINIK RATIU, INGO GOTTSCHALK, \\ BERND MORGENSTERN, JUDITH SARAH ABEL, CHRISTIAN EICHLER, \\ CAROLINE PAHMEYER, SEBASTIAN LUDWIG, PETER MALLMANN and FABINSHY THANGARAJAH
}

Department of Obstetrics and Gynecology, University Hospital Cologne and Medical Faculty, Cologne, Germany

\begin{abstract}
Background/Aim: For many years clinical research has been concerned with doppler sonography as a non-invasive tool for intrauterine fetal status assessment. A new focus is now placed on the measurement of cerebroplacental index (CPR) as a predictor of fetal outcome. Our aim was to investigate the relationship between the cerebroplacental ratio $(C P R)$, the delivery mode and the fetal outcome in singleton pregnancies. Patients and Methods: A retrospective cohort study of pregnancies in which doppler sonography of middle cerebral artery (MCA) and umbilical artery (UA) was conducted up to 9 weeks before delivery took place. Patients with pathological $(C P R \leq 1.0)$ and normal $C P R(>1.0)$ were compared by umbilical cord $p H, A P G A R$ scores, birth weight, delivery week and delivery mode. Results: A total of 2,270 singleton pregnancies were included. The APGAR score for 1, 5 and 10 minutes and the gestational age at delivery were significantly lower in the group of patients with pathological CPR $(p<0.001)$. Overall, $50 \%$ of the cohort had a cesarean section, the difference between the groups was statistically significant $(p<0.001)$, with a higher amount of cesareans in the group of patients with pathological $C P R$. The multiple regression analysis showed a significantly improved $p H$ of delivery when cesarean section $(p<0.001)$, female sex of fetus $(p=0.013)$ and higher CPR $(p=0.035)$ were present. Conclusion: The measurement of $C P R$ is an important, non-invasive predictive parameter and leads to the identification of a risk collective even in the non-selected patient population and thus probably to a reduction of perinatal morbidity.
\end{abstract}

This article is freely accessible online.

*These Authors contributed equally to this work.

Correspondence to: Fabinshy Thangarajah, Department of Obstetrics and Gynecology, Medical Faculty, University Hospital Cologne, Kerpener Str. 34, 50931 Cologne, Germany. Tel: +49 22147886545, Fax: +49 22147886546, e-mail: Fabinshy.Thangarajah@uk-koeln.de

Key Words: CPR, fetal outcome, doppler sonography.
For many years clinical research has been concerned with doppler sonography as a non-invasive tool for intrauterine fetal status assessment. A new focus is now placed on the measurement of cerebroplacental index (CPR) as a predictor of fetal outcome. The cerebro-placental ratio is the ratio of the two doppler sonographic parameters, the pulsatility index (PI) of the middle cerebral artery (MCA-PI) and PI of the umbilical artery (UA-PI). Furthermore, it shows even discrete changes in the perfusion of only one of the two vessels as an index of two different vessels. The CPR values are nearly constant throughout the last ten weeks of pregnancy (1), however, it is known that pathological CPR is associated with an increased risk of perinatal complications, in particular, neonatal acidosis, lower birth weight, and a poorer APGAR score (1-4).

The purpose of this study was to investigate the relationship between the cerebroplacental ratio (CPR), the delivery mode and the fetal outcome in singleton pregnancies in a tertiary center institution.

\section{Patients and Methods}

This is a hospital based retrospective analysis of pregnant patients who underwent an ultrasound examination up to 9 weeks before delivery at the department of gynecology and obstetrics at the University Hospital of Cologne between 2011 and 2018. The inclusion criteria were: i) a non-anomalous singleton pregnancy, ii) the absence of fetal or maternal contraindications concerning vaginal delivery and iii) a recorded UA PI and MCA PI. The following prenatal parameters were evaluated: i) maternal age, ii) gestational age at point of ultrasound examination determined by last menstrual period, iii) estimated fetal weight calculated using Hadlock's formula (5), and iv) the cerebroplacental ratio calculated by dividing mean MCA PI by mean UA PI. The doppler measurement of MCA and UA was performed in a standardized procedure by an investigator, graded DEGUM level II or III (6).

Furthermore, umbilical arterial $\mathrm{pH}$, APGAR score at 1, 5 and 10 minutes, mode of delivery, fetal sex, birth weight were analyzed. According to the PROTO study, pathological CPR was defined as $<1.0$ (7).

Statistical analysis was performed using IBM SPSS, Version 24. For the mean comparisons of the two groups of interval scaled variables, a $t$-test for independent samples was used. With a 
sample size of more than 30 subjects per subgroup, an asymptotic normal distribution is assumed. The APGAR score at 1,5 , and 10 minutes between patients with a pathological and a normal CPR was compared as an ordinal variable with the Mann-Whitney- $U$ test. Furthermore, a chi-square test was used to analyze differences in the acidosis frequency between patients with the pathological and the normal cerebroplacental index. The comparison of the umbilical cord $\mathrm{pH}$ value in three groups (primary, secondary cesarean or vaginal delivery) was carried out with a one-factorial variance analysis with a Bonferroni correction in Post-hoc tests in the case of homogeneous variances and a Games-Howell correction of the alpha error for inhomogeneous variances. The APGAR score for 1, 5 and 10 minutes was tested for these three groups using the Kruskal-Wallis test. A multivariate linear regression analysis assessed the influence of the variable delivery mode, the pediatric gender, the CPR and the patient's age on the $\mathrm{pH}$ value. A $p$-Value $<0.05$ was considered significant for all calculations.

\section{Results}

A total of 2,270 patients were included in this retrospective analysis, according to the inclusion criteria mentioned above. A pathological CPR $(<1.0)$ in the cohort was found in 126 , a normal CPR $(>1.0)$ in 2144 patients. Patients' characteristics are demonstrated in Table I.

The mean gestational week of delivery was 37 in the group of patients with pathological CPR and 39 in the group of patients with normal CPR. There was a significant difference between the two CPR groups, according to the gestational week at birth $(p<0.001)$.

APGAR score. The one-, five- and ten-minute APGAR score was investigated in both study cohorts. We noticed a significant difference in APGAR one, five and ten minutes between patients with pathological and normal CPR, where patients with pathological CPR displayed a lower APGAR score $(p<0.001)$.

Acidosis. In the group of pathological CPR, $21.5 \%$ of the newborns showed an acidosis ( $\mathrm{pH} \leq 7.25)$ compared to $28.4 \%$ in the normal group $(p=0.118)$. A severe acidosis $(\mathrm{pH} \leq 7.10)$ was found in $4.1 \%$ of all newborns, in the pathological CPR group compared to $2.5 \%$ in the group with normal CPR $1.6 \%$ $(p=0.452)$, respectively.

Mode of delivery. In total, $41.2 \%$ of the patients had a spontaneous delivery, whereas $9.6 \%$ had a vaginal operative delivery and $49.3 \%$ underwent a cesarean section.

When we compared all three types of delivery mode of patients with pathological and normal CPR the difference was significant $(p<0.001)$.

The comparison of patients with spontaneous delivery versus vaginal operative delivery showed no significant difference in the cerebroplacental index $(p=0.616)$.
Fetal birthweight. The fetal birthweight was significantly lower in patients with pathological CPR compared to patients with normal CPR $(2,436 \mathrm{~g}$ versus $3,136 \mathrm{~g} ; p<0.001)$.

Multiple regression analysis. In the multiple regression analysis we examined the influence of delivery mode, gender of fetus, CPR and patient age on the $\mathrm{pH}$ value. There was a significantly improved umbilical cord $\mathrm{pH}$ for patients with cesarean section $(p<0.001)$, a significantly improved umbilical cord $\mathrm{pH}$ in female fetuses $(p=0.013)$ and a positive influence of the CPR on the umbilical cord $\mathrm{pH}(p=0.035)$; higher values for the CPR index was associated with a higher umbilical cord $\mathrm{pH}$. The age of the patient had no significant influence on the $\mathrm{pH}(p=0.745)$ (Table II).

\section{Discussion}

In this retrospective hospital-based study we analyzed 2,270 patients with singleton pregnancies according to their outcome depended on the CPR. The current analysis showed a significant difference between both groups with regards to the mode of delivery $(p<0.001)$. Fiona et al., have examined 1,902 singleton pregnancies undergoing induction of labor at $\geq 37$ weeks' gestation in a prospective analysis. They were able to demonstrate that low CPR, measured within 24 hours of induction of labor, is associated with increased risk of cesarean section for fetal distress and adverse neonatal outcome (8).

Furthermore, other authors have also confirmed that fetuses with an abnormal CPR that are appropriate for gestational age or have late-onset small gestational age SGA (>34 weeks of gestation) have a higher incidence of fetal distress in labor requiring emergency cesarean delivery $(1,9-15)$.

Apart from the maternal outcome we also analyzed the fetal outcome by examining the incidence of acidosis, the APGAR score and birthweight of neonates. We found significantly lower APGAR scores at 1,5 and 10 minutes in the group of patients with pathologic CPR compared to the group of patients with normal CPR $(p<0.001)$. Reduced APGAR scores at delivery in patients with low CPR can be confirmed by Gramellini et al., who found that Apgar $<7$ at 5 min was significantly higher in patients with abnormal CPR $16.6 \%$ versus $2.7 \%(p<0.001)(1)$.

Additionally, we were able to show that pregnancies with lower CPR were associated with lower birthweight. Although this has also been described by Flood et al., it has to be stressed that patients with low CPR delivered significantly at an earlier stage, which could also explain the lower birthweights (7). Surprisingly, the incidence of acidosis was not statistically different between the two groups, which is contrast to the findings of Morales-Rossello et al. They analyzed whether SGA and appropriate-for-gestational-age (AGA) term fetuses with a low CPR have a worse neonatal 
Table I. Patient characteristics.

\begin{tabular}{|c|c|c|c|c|}
\hline & All patients & Pathological CPR & Normal CPR & $p$-Value \\
\hline Maternal age at delivery (years) & $32.42 \pm 5,42$ & $31.98 \pm 5,6$ & $32.44 \pm 5,4$ & 0.354 \\
\hline Gestational age at delivery (weeks) & $38.13 \pm 1,92$ & $36.53 \pm 2,53$ & $38.22 \pm 1,83$ & $<0.001$ \\
\hline Fetal birthweight $(\mathrm{g})$ & $3097 \pm 659$ & $2436 \pm 760$ & $3135 \pm 632$ & $<0.001$ \\
\hline Umbilical cord $\mathrm{pH}$ & $7.284 \pm 0.079$ & $7.286 \pm 0.074$ & $7.283 \pm 0.079$ & 0.786 \\
\hline Severe fetal acidosis* $\mathrm{n}$ & $37(4.1 \%)$ & $3(2.5 \%)$ & $34(1.6 \%)$ & 0.452 \\
\hline Fetal acidosis all forms* $\mathrm{n}$ & $620(27.3 \%)$ & $26(21.5 \%)$ & $594(28.4 \%)$ & 0.118 \\
\hline Male gender $(n)$ & $1154(50.8 \%)$ & $67(53.2 \%)$ & $1087(50.8 \%)$ & 0.798 \\
\hline APGAR & & & & $<0.001$ \\
\hline 1 min APGAR & $8.17 \pm 1.53$ & $7.44 \pm 1.82$ & $8.22 \pm 1.50$ & \\
\hline 5 min APGAR & $9.21 \pm 1.24$ & $8.56 \pm 1.47$ & $9.24 \pm 1.22$ & \\
\hline 10 min APGAR & $9.56 \pm 0.89$ & $9.21 \pm 1.13$ & $9.58 \pm 0.87$ & \\
\hline Delivery mode & & & & $<0.001$ \\
\hline Spontanous delivery & $935(41.2 \%)$ & $27(21.4 \%)$ & $908(42.4 \%)$ & \\
\hline Vaginal operative delivery & $217(9.6 \%)$ & $9(7.1 \%)$ & $208(9.7 \%)$ & \\
\hline Cesarean section & $1118(49.3 \%)$ & $90(71.4 \%)$ & $1028(47.9 \%)$ & \\
\hline
\end{tabular}

*Severe fetal acidosis ( $\mathrm{pH} \leq 7.10)$; fetal acidosis all forms $(\mathrm{pH} \leq 7.25)$.

Table II. Multiple regression analysis.

\begin{tabular}{lcc}
\hline & Regression coefficient & $p$-Value \\
\hline Vaginal delivery versus cesarean section & 0.04 & 0.000 \\
Gender & 0.01 & 0.013 \\
CPR & 0.01 & 0.035 \\
Age of patients & 0.01 & 0.745 \\
\hline
\end{tabular}

acid-base status compared to those with a normal CPR (16). The different results could be explained by the different selection of the study cohort. The study population of Morales-Rosello et al., had an ultrasound scan within 14 days of delivery in contrast to the present study, which included examination up to 8 weeks before delivery (16).

The retrospective character has to be considered as a limitation of this study. The data of this study were collected during a non-routine procedure in Germany. The rate of SGA fetuses might be slightly higher compared to the overall population due to the status of this hospital. Nevertheless, the high quality of measurements by experienced physicians and the analysis of data obtained from a tertiary care hospital has to be considered as a strength of the study. In conclusion, the measurement of CPR is an important non-invasive predictive parameter of adverse fetal outcome and enables identification of high-risk patients even in the non-selected patient population, which could possibly lead to a reduction in perinatal morbidity. Pathological CPR makes it necessary to discuss the mode of delivery and admit patients to specialized delivery units with neonatal care units in order to prevent postpartum transfers. As the mode of delivery seems to correlate with the arterial umbilical cord $\mathrm{pH}$, this has to be taken into consideration for planning the delivery.

\section{Conflicts of Interest}

The Authors declare that they have no conflict of interest.

\section{Authors' Contributions}

BG was involved with project development and manuscript writing, JR with manuscript writing, data collection and statistical analysis, DR, IG, BM, JSA, CE, CP, SL and PM with manuscript editing and data collection, and FT with manuscript writing, data collection and project development.

\section{References}

1 Gramellini D, Folli MC, Raboni S, Vadora E and Merialdi A: Cerebral-umbilical Doppler ratio as a predictor of adverse perinatal outcome. Obstet Gynecol 79: 416-420, 1992. PMID: 1738525.

2 Jugović D, Tumbri J, Medić M, Jukić MK, Kurjak A, Arbeille P and Salihagić-Kadić A: New Doppler index for prediction of perinatal brain damage in growth-restricted and hypoxic fetuses. Ultrasound Obstet Gynecol 30: 303-311, 2007. PMID: 177218 70. DOI : $10.1002 /$ uog.4094

3 Arabin B, Goerges $\mathrm{J}$ and Bilardo CM: The importance of the cerebroplacental ratio in the evaluation of fetal well-being in SGA and AGA fetuses. Am J Obstet Gynecol 214: 298-299, 2016. PMID: 26454127. DOI: 10.1016/j.ajog.2015.09.098 
4 Khalil A, Morales-Rosello J, Khan N, Nath M, Agarwal P, Bhide A, Papageorghiou A and Thilaganathan B: Is cerebroplacental ratio a marker of impaired fetal growth velocity and adverse pregnancy outcome? Am J Obstet Gynecol 216: 606.e1-606.e10, 2017. PMID: 28189607. DOI : 10.1016/j.ajog.2017.02.005

5 Hadlock FP, Harrist RB and Martinez-Poyer J: In utero analysis of fetal growth: a sonographic weight standard. Radiology 181: 129-133, 1991. PMID: 1887021. DOI: 10.1148/radiology.181.1. 1887021

6 Faber R, Heling K-S, Steiner H and Gembruch U: Doppler Sonography during Pregnancy - DEGUM Quality Standards and Clinical Applications. Ultraschall Med Stuttg Ger 1980 40: 319325, 2019. PMID: 30895584. DOI: 10.1055/a-0800-8596

7 Flood K, Unterscheider J, Daly S, Geary MP, Kennelly MM, McAuliffe FM, O’Donoghue K, Hunter A, Morrison JJ, Burke G, Dicker P, Tully EC and Malone FD: The role of brain sparing in the prediction of adverse outcomes in intrauterine growth restriction: results of the multicenter PORTO Study. Am J Obstet Gynecol 211: 288.e1-5, 2014. PMID: 24813969. DOI: 10.1016/ j.ajog.2014.05.008

8 Fiolna M, Kostiv V, Anthoulakis C, Akolekar R and Nicolaides $\mathrm{KH}$ : Prediction of adverse perinatal outcome by cerebroplacental ratio in women undergoing induction of labor. Ultrasound Obstet Gynecol 53: 473-480, 2019. PMID: 30426578. DOI: 10.1002/ $\operatorname{uog} .20173$

9 Bligh LN, Al Solai A, Greer RM and Kumar S: Diagnostic performance of cerebroplacental ratio thresholds at term for prediction of low birthweight and adverse intrapartum and neonatal outcomes in a term, low-risk population. Fetal Diagn Ther 43: 191198, 2018. PMID: 28746928. DOI: 10.1159/00 0477932

10 Akolekar R, Ciobanu A, Zingler E, Syngelaki A and Nicolaides $\mathrm{KH}$ : Routine assessment of cerebroplacental ratio at 35-37 weeks' gestation in the prediction of adverse perinatal outcome. Am J Obstet Gynecol 221: 65.e1-65.e18, 2019. PMID: 30878322. DOI: $10.1016 /$ j.ajog.2019.03.002
11 Arias F: Accuracy of the middle-cerebral-to-umbilical-artery resistance index ratio in the prediction of neonatal outcome in patients at high risk for fetal and neonatal complications. Am J Obstet Gynecol 171: 1541-1545, 1994. PMID: 7802064.

12 Bahado-Singh RO, Kovanci E, Jeffres A, Oz U, Deren O, Copel $\mathrm{J}$ and Mari G: The Doppler cerebroplacental ratio and perinatal outcome in intrauterine growth restriction. Am J Obstet Gynecol 180: 750-756, 1999. PMID: 10076158.

13 Makhseed M, Jirous J, Ahmed MA and Viswanathan DL: Middle cerebral artery to umbilical artery resistance index ratio in the prediction of neonatal outcome. Int J Gynaecol Obstet 71: 119125, 2000. PMID: 11064008 .

14 DeVore GR: The importance of the cerebroplacental ratio in the evaluation of fetal well-being in SGA and AGA fetuses. Am J Obstet Gynecol 213: 5-15, 2015. PMID: 26113227. DOI: 10.1016/j.ajog.2015.05.024

15 Triunfo S, Crispi F, Gratacos E and Figueras F: Prediction of delivery of small-for-gestational-age neonates and adverse perinatal outcome by fetoplacental Doppler at 37 weeks' gestation. Ultrasound Obstet Gynecol 49: 364-371, 2017. PMID: 27241184. DOI: 10.1002/uog.15979

16 Morales-Roselló J, Khalil A, Morlando M, Bhide A, Papageorghiou A and Thilaganathan B: Poor neonatal acid-base status in term fetuses with low cerebroplacental ratio. Ultrasound Obstet Gynecol 45: 156-161, 2015. PMID: 25123254. DOI: 10.1002/uog.14647
Received June 17, 2019 Revised July 1, 2019 Accepted July 10, 2019 